\title{
Survey of Haloacetic Acids in Household Drinking Water Produced from Thermal Desalination in Kuwait
}

\author{
H.F. Al-Mudhaf ${ }^{1}$, A.I. Abu-Shady ${ }^{*}, 1$, M.I. Selim ${ }^{2}$ and F.A. Alsharifi ${ }^{3}$ \\ ${ }^{1}$ College of Technological Studies, Public Authority for Applied Education and Training (PAAET), P.O. Box 97, \\ Dasman 15451, Kuwait \\ ${ }^{2}$ College of Health and Human Performance, East Carolina University, 3409 Carol Belk Building, Greenville, NC \\ 27858-4353, USA \\ ${ }^{3}$ College of Health Sciences, PAAET, P.O. Box 14281, Faiha 72853, Kuwait
}

\begin{abstract}
The main objectives of this study were to survey and document the existence of haloacetic acids (HAAs) in Kuwait drinking water. Levels of HAAs were determined in 516 samples collected from residential and government buildings and 51 brands of bottled water from December 2003 to May 2005. In household water, the levels of HAA5 were found to be between $85 \%$ and $99 \%$ (average of $95 \%$ ) of the levels of total HAAs. HAA5 levels exceeded the MCL of USEPA in $8 \%$ of the samples. The average percent increase of these levels was $106 \%$ of the MCL value. The use of charcoal filters showed significant efficiency in decreasing HAAs levels. The percent dominance frequencies of HAA5 components were in the order TCAA, MCAA, MBAA, DBAA, and DCAA with values 43\%, 23\%, 22\%, 9\% and 4\%, respectively. Strong correlations between residual chlorine and HAA5 levels were observed. Seasonal variations indicated that HAA5 levels were much higher in the summer than in the winter.
\end{abstract}

Keywords: Chlorination byproducts, haloacetic acids, seasonal variations, drinking water, desalination, Kuwait.

\section{INTRODUCTION}

A major objective of drinking water treatment is to provide water that is both microbiologically and chemically safe for human consumption. The destruction of microbial pathogens is essential and very commonly involves the use of reactive chemical disinfectant such as chlorine. Disinfection reduces the risk of pathogenic infection, but also may pose a chemical threat to human health due to disinfection residues and the formation of a group of chemical compounds known as disinfection byproducts (DBPs). Since the 1970s, research in the drinking water field has focused on documenting and understanding the occurrence of DBPs in drinking water. DBPs are formed when disinfectants react with natural organic matter (NOM) and/or inorganic substances (precursors) present in water [16]. More than 250 DBPs have been identified, but the behavioral profiles of only about 20 of these DBPs are adequately understood [7]. Trihalomethanes (THMs) and haloacetic acids (HAAs) are the most prevalent groups of chlorinated DBPs (CDBPs) found in drinking water. HAAs, which are formed from organic material during water chlorination, include the following acids: monochloroacetic (MCAA), dichloroacetic (DCAA), trichloroacetic (TCAA), monobromoacetic (MBAA), dibromoacetic (DBAA), tribromoacetic (TBAA), bromochloroacetic (BCAA), bromodichloroacetic (BDCAA), and chlorodibromoacetic

*Address correspondence to this author at the Ibn Al-Haitham In-Service Training Center, P. O. Box 43886 Hawalli, 32053, PAAET, Kuwait; Tel.: +965 6664 8195; Fax: +965 2257 0843;

E-mails: aasattar44@yahoo.com, ai.abushady@paaet.edu.kw
(CDBAA). Collectively these compounds are usually known as total HAAs (THAAs). Potential adverse health effects from exposure to some of these compounds have been identified by epidemiological $[4,8-11]$ and toxicological $[12$, 13] studies. The most prevalent of these acids are DCAA and TCAA, while the others are typically found at lower concentrations in drinking water. In the United States (US), MCAA, DCAA, TCAA, MBAA and DBAA together are commonly denoted as HAA5.

Exposure to HAAs is associated with an increased risk of bladder and colon cancer $[10,14]$ in addition to reproductive effects such as intrauterine growth retardation, low birth weight, preterm birth, congenital malformations, and stillbirth $[3,4,11,15-17]$. THAA concentrations and the formation of individual HAA components in chlorinated water strongly depend on the composition of raw water, operational parameters, and the presence of residual chlorine in the distribution system [11, 18-20].

A great number of studies have been conducted worldwide to evaluate the HAAs in drinking water produced from surface and/or ground water. However, a literature survey indicated that only two studies have addressed the topic when the source of drinking water is seawater and the treatment process is thermal desalination [21, 22]. These studies have been conducted in two Arabian Gulf countries (Saudi Arabia (SA) and United Arab Emirates (UAE)), but none in Kuwait, even though all Gulf countries rely heavily on the desalination of seawater as their primary source of drinking water. In SA, Dalvi et al. [21] studied the effect of chlorine concentrations, total organic carbon and bromide concentration on the formation potential of HAAs in 
seawater (fed to desalination plants), product water from multi-stage flash (MSF) desalination plants, and well water used for blending and blended water. They found that the mean values of THAAs in seawater, product water and blended water were $7.0,1.56$ and $2.4 \mu \mathrm{g} / \mathrm{L}$, respectively. In the second study, El-Shorbagy and Abdulkarim [22] analyzed CDBPs in drinking water produced from desalination in UAE. They reported that desalination plant intake water samples showed lower levels of HAA5 than the equipment quantification limit of $1.0 \mu \mathrm{g} / \mathrm{L}$. Except for DBAA, which was found between 0.52 and $13.4 \mu \mathrm{g} / \mathrm{L}$, the inside and downstream samples of the desalination plant showed nominal levels of HAA5 components.

The dual purpose power and desalination plants along the Kuwait coast are MSF distillation plants producing distilled water, which is next blended with $5-10 \%$ brackish water to make it potable, and then chlorinated and pumped to the distribution system network where consumers have further storage facilities. For domestic or public premises, these facilities are mainly roof tanks $\left(6-12 \mathrm{~m}^{3}\right)$ constructed from fiberglass or polyethylene, in addition to ground reservoirs $\left(20-100 \mathrm{~m}^{3}\right)$ for large buildings. This situation is mainly found in the Arabian Gulf countries, but is rarely encountered in other regions of the world [23].

A literature survey indicated that no studies have been carried out to investigate the existence and levels of HAAs in drinking water supplied by the five MSF desalination plants in Kuwait. Routine chemical analyses of outdoor and indoor drinking water in Kuwait are currently performed by labs of the Ministry of Electricity and Water (MEW) and the Environmental Protection Authority (EPA), respectively. Bottled water is the responsibility of the Public Health labs of the Ministry of Public Health (MPH) in Kuwait. However, none of these labs have facilities for monitoring HAAs, and the monthly reports published to date do not include data on HAAs. Thus, this study is important for documenting the presence and levels of HAAs in drinking water in Kuwait.

The objectives of this study were to: 1) survey and document the existence and levels of HAAs in indoor and outdoor household drinking water in various areas of Kuwait; 2) correlate these levels with the coastal source of desalinated water; 3) study the effect of seasonal variations on THAA levels; 4) study the occurrence of HAAs in bottled water brands available in Kuwait market; and 5) determine whether values exceed the maximum levels recommended by the US Environmental Protection Agency (US-EPA).

\section{MATERIALS AND METHODS}

\section{Sampling}

Water samples were collected from private residencies (houses and apartments) and government buildings at 99 locations in 69 neighborhoods of the six governorates of the State of Kuwait. One sampling location was selected for repeated sampling within each of the 69 neighborhoods; these are designated as primary sampling locations. Of the same 69 locations (buildings) in the 69 neighborhoods, an additional 30 locations (in 30 of the 69 neighborhoods) were selected for one-time sampling; these are designated as secondary sampling locations. Fig. (1) shows the distribution of all sampling locations within various governorates as well as the desalination plants. Two sampling points, outdoor and indoor, are defined at each location. Three replicates of each sample were collected and preserved according to US-EPA method 552.2 [24]. Samples were delivered to the laboratory in dry ice cooled boxes and stored refrigerated (at $4^{\circ} \mathrm{C}$ ) upon arrival until extraction and analysis were completed. All water samples were extracted, and the extracts were analyzed within the recommended holding times, and any sample exceeding those holding times was discarded.

Fifty-one brands of bottled water were collected from supermarkets and food stores in Kuwait; this water was sampled, preserved and analyzed as described above.

\section{Analytical Procedure}

Volatile- and organic-free water obtained from the Millipore Ultra Pure Water Purification System (Millipore, Bedford, MA, USA) was used for all required preparations. Certified high-purity organic solvents, chemical reagents, calibration standards and check standards were purchased from Honeywell Burdick \& Jackson (NJ, USA), Merck (Nottingham, UK), Supelco (Germany) and AccuStandard (CT, USA), respectively. Helium and nitrogen gases were certified Grade 6 of purity 99.9999\% supplied by Air products (Belgium).

For all collected samples, water quality parameters which include residual chlorine, temperature, $\mathrm{pH}$, and conductivity are measured on-site at the time of collection. Bromide ion is determined according the USEPA method 300.1[24], using Waters gradient HPLC system (Waters, Milford, MA, USA) equipped with Waters 432 conductivity detector, Altech 1000HP Autosuppressor, and Waters 2690 Separations Module. Analytical separation of bromide ion is performed on 4.6 x $75 \mathrm{~mm}$ IC-PAK-Anion HR analytical column. Dedicated guard column and the suppressor system are used in connection with the analytical column. A mixture of 0.10 $\mathrm{mM} \mathrm{Na}_{2} \mathrm{CO}_{3} / 0.01 \mathrm{mM} \mathrm{NaHCO}_{3}$ is used as the mobile phase for the separation of anions.

HAAs were determined by using Agilent 6890 Gas Chromatography (GC) equipped with two micro-electron capture detectors ( $\mu \mathrm{ECD}$ ) (Agilent Technologies Inc., Santa Clara, CA, USA) according to US-EPA method 552.2 [24]. According to this method, a $40 \mathrm{~mL}$ water sample was adjusted to $\mathrm{pH}<0.5$ and extracted with $4 \mathrm{~mL}$ of methyl-tertbutyl-ether (MTBE). The haloacetic acids and dalapon that were partitioned into the organic phase were then converted to their methyl esters by the addition of acidic methanol followed by slight heating. The acidic extract was neutralized by a back extraction with a saturated solution of sodium bicarbonate, and the target analytes were identified and measured by the GC/ $\mu$ ECD. Two columns (A and B) were used. The two inlets of the primary column A (J\&WDB-35ms: $30 \mathrm{~m}$ length $\mathrm{x} \quad 0.32 \mu \mathrm{m}$ id $\mathrm{x} \quad 0.25 \mu \mathrm{m}$ film thickness) and the confirmation column B (J\&W- DB-XLB: $30 \mathrm{~m}$ length $\times 0.32 \mu \mathrm{m}$ id $\times 0.5 \mu \mathrm{m}$ film thickness) were connected to the same injection inlet of the GC through an inert fused silica Y-shape splitter, while the two outlets were connected to the two $\mu$ ECDs. The carrier and make-up gases were helium and nitrogen, respectively. Separation conditions were as follows: the injection technique was splitless with a 30 second delay; the injector temperature was $200^{\circ} \mathrm{C}$; the $\mu \mathrm{ECDs}$ temperature was $260^{\circ} \mathrm{C}$; and the helium 


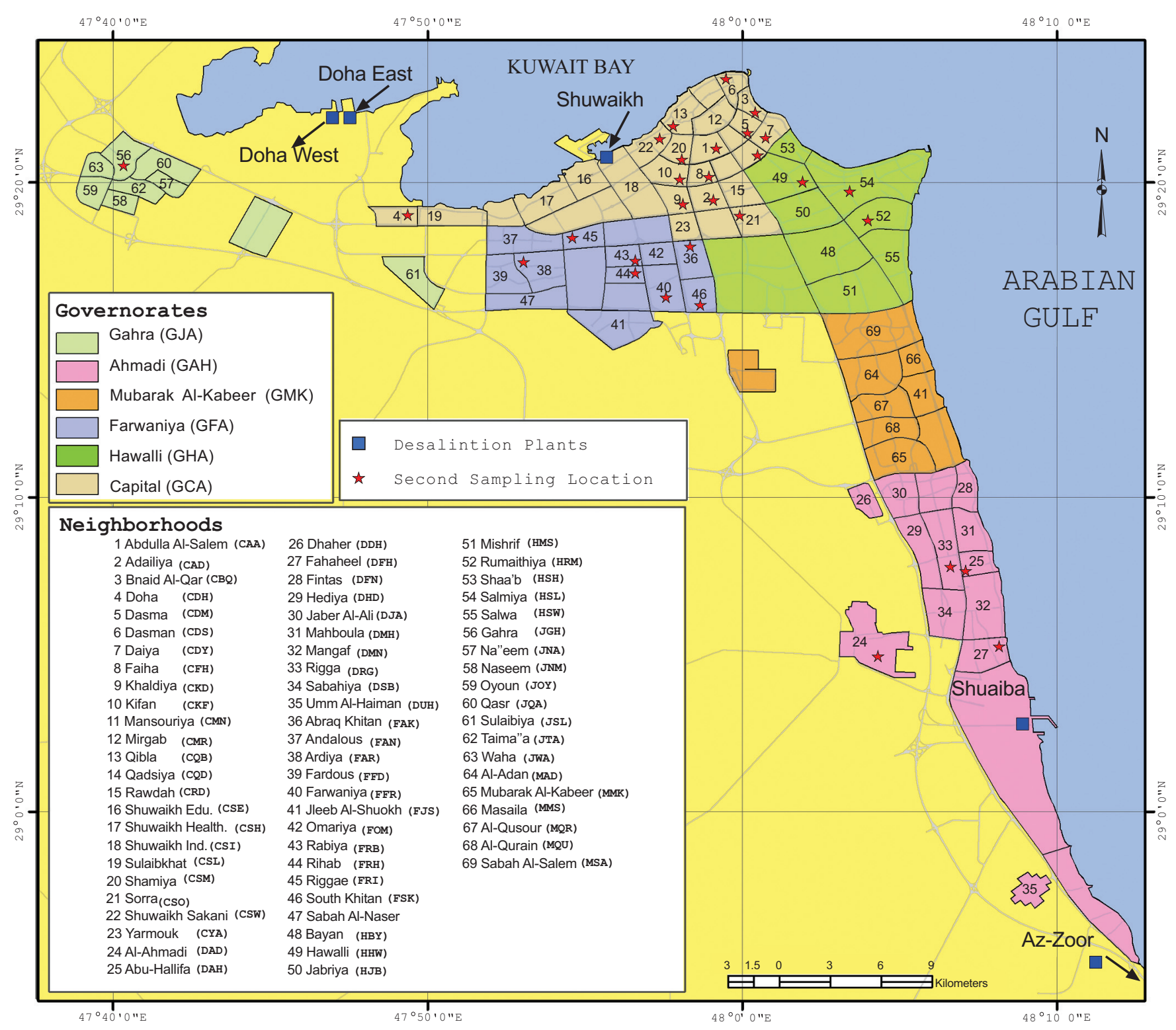

Fig. (1). Location of desalination plants and distribution of sampling Locations within different neighborhoods of the Governorates of Kuwait.

linear velocity was $24 \mathrm{~cm} / \mathrm{sec}$ at $35^{\circ} \mathrm{C}$. The oven program was as follows: hold at $35^{\circ} \mathrm{C}$ for 10 minutes, increase to $75^{\circ} \mathrm{C}$ at $5^{\circ} \mathrm{C} / \mathrm{min}$ and hold 15 minutes, increase to $100^{\circ} \mathrm{C}$ at $5^{\circ} \mathrm{C} / \mathrm{min}$ and hold five minutes, increase to $135^{\circ} \mathrm{C}$ at $5^{\circ} \mathrm{C} / \mathrm{min}$ and hold two minutes. Analytes were quantified using procedural standard calibration. The concentrations of each HAA component were measured by relating its $\mu \mathrm{ECD}$ response produced to the $\mu E C D$ response produced by a compound used as an internal standard. Surrogate analytes, whose concentrations were known in every sample, were measured with the same internal standard calibration procedure.

Quality control (QC) for the nine HAAs and dalapon was performed according to the conditions specified by US-EPA method 552.2 [24]. This includes analysis of laboratory reagents and field blanks, fortified blanks, and samples as a continuous check of performance. Rinse blanks and six calibrated standard solutions of all monitored analytes were used at $\mathrm{ppb}$ concentrations for the different analytes and as specified in the method. To confirm the performance of lab analyses, split QC samples were submitted for analysis at the University of Iowa Hygienic Lab (UHL, Iowa City, IA, USA) in January and July 2004. Our lab results agreed with those of the UHL within $\pm 5-10 \%$ for various HAAs.

\section{RESULTS AND DISCUSSION}

\section{Household Water}

In Kuwait, chlorine is currently the only disinfectant used in water treatment in order to reduce the risk of pathogenic infection. Chlorine forms HAAs and THMs as the main 
groups of CDBPs, which may pose a chemical threat to human health. THM levels and their seasonal variation in drinking water produced from thermal desalination in Kuwait were extensively studied [23]. The US-EPA has established a maximum contaminant limit (MCL) of $60 \mu \mathrm{g} / \mathrm{L}$ for HAA5 [25].

In order to generate robust data on HAAs, its levels were determined in 516 water samples collected from three groups of locations, covering the residential areas in various governorates of Kuwait during the time period from December 2003 to May 2005. In addition, water quality parameters (temperature, $\mathrm{pH}$, and TDS), residual chlorine, and bromide concentrations were also measured. As shown in Table 1 (columns 1 and 2), these groups are: i) Group A, consisting of six locations at Shuwaikh Education (CSE), Shuwaikh Sakani (CSW), Umm Al-Haiman (DUH), Riggae (FRI), Salmiya (HSL) and Oyoon (JOY). These locations were sampled between 12 and 16 times to provide a total of 171 samples; ii) Group B, consisting of six locations at Kifan (CKF), Qibla (CQB), Shuwaikh Health (CSH), Sulaibikhat (CSL), Sorra (CSO) and Ardiya (FAR). These locations were sampled between six and nine times to provide a total of 83 samples; iii) Group C, consisted of 16, 31, 16, 10, 8 and 6 locations from Ahmadi (GAH), Capital (GCA), Farwaniya (GFA), Hawalli (GHA), Jahra (GJA) and Mubarak AlKabeer (GMK) governorates, respectively. These locations were sampled between one and three times to provide a total of 262 samples. At each sampling collection time, two samples were collected from two points of each selected building on each occasion, one from the water connection just outside the building prior to water flow into the building (outdoor; designated by the letter $\boldsymbol{O}$ ) and the second from an inside tap after the drinking water had passed through the underground reservoir, plumbing, and rooftop storage tank of the building (indoor; designated by the letter $\boldsymbol{I}$ ). Locations and governorates with their abbreviations are shown in Fig. (1).

During the course of this study and according to official information from the Ministry of Electricity and Water in Kuwait (MEW), the five dual purpose power and desalination plants along Kuwait coast (Fig. 1) are multistage flash (MSF) distillation plants and producing a total of

Table 1. Statistical Summary of HAA5 Concentrations $(\mu \mathrm{g} / \mathrm{L})$ for the Indoor $(I)$ and Outdoor $(O)$ Samples Collected During the Time Period from December 2003 to May 2005

\begin{tabular}{|c|c|c|c|c|c|c|c|c|c|}
\hline \multirow{2}{*}{$\begin{array}{l}\text { Sampling } \\
\text { Location }\end{array}$} & \multirow{2}{*}{$\begin{array}{l}\text { No. of } \\
\text { Samples: } \\
\text { I (O) })^{\mathrm{a}}\end{array}$} & \multicolumn{2}{|c|}{ Mean \pm S. D. } & \multicolumn{2}{|c|}{ Median } & \multicolumn{2}{|c|}{ Minimum } & \multicolumn{2}{|c|}{ Maximum } \\
\hline & & $I$ & $O$ & $I$ & $O$ & $I$ & $O$ & $I$ & $O$ \\
\hline \multicolumn{10}{|l|}{ Group $A^{b}$} \\
\hline CSE & $12(13)$ & $40.50 \pm 66.55$ & $37.95 \pm 56.44$ & 9.19 & 7.95 & 5.51 & 1.21 & 190.07 & 157.66 \\
\hline CSW & $15(15)$ & $50.22 \pm 85.84$ & $30.87 \pm 48.24$ & 6.52 & 5.91 & 2.50 & 2.65 & 255.97 & 137.82 \\
\hline DUH & $13(13)$ & $16.78 \pm 20.28$ & $17.80 \pm 20.90$ & 4.57 & 7.69 & 1.29 & 2.60 & 63.71 & 67.42 \\
\hline FRI & $15(14)$ & $22.22 \pm 39.28$ & $24.12 \pm 37.42$ & 5.54 & 6.40 & 1.30 & 2.04 & 117.26 & 115.03 \\
\hline HSL & $16(16)$ & $23.01 \pm 36.21$ & $24.09 \pm 33.34$ & 5.67 & 7.19 & 1.46 & 2.31 & 106.15 & 98.82 \\
\hline JOY & $15(14)$ & $31.11 \pm 39.20$ & $36.34 \pm 52.43$ & 9.70 & 9.38 & 5.35 & 2.50 & 126.40 & 158.33 \\
\hline \multicolumn{10}{|l|}{ Group B ${ }^{c}$} \\
\hline CKF & 7 (7) & $7.68 \pm 2.39$ & $8.16 \pm 1.89$ & 7.45 & 8.14 & 3.78 & 5.63 & 11.20 & 11.33 \\
\hline CQB & $9(9)$ & $2.24 \pm 1.73$ & $3.13 \pm 1.54$ & 1.90 & 3.11 & 0.54 & 1.21 & 5.44 & 6.07 \\
\hline $\mathrm{CSH}$ & $6(6)$ & $4.38 \pm 1.18$ & $3.51 \pm 2.08$ & 4.18 & 3.90 & 3.06 & 0.65 & 5.92 & 5.89 \\
\hline CSL & $6(6)$ & $5.76 \pm 2.99$ & $4.90 \pm 2.02$ & 5.12 & 4.75 & 2.40 & 2.90 & 10.59 & 8.36 \\
\hline $\mathrm{CSO}$ & $7(7)$ & $9.16 \pm 2.79$ & $10.05 \pm 4.25$ & 8.96 & 9.77 & 6.30 & 4.67 & 13.00 & 15.10 \\
\hline FAR & $6(7)$ & $8.41 \pm 3.70$ & $5.94 \pm 3.46$ & 7.11 & 5.31 & 4.79 & 2.64 & 13.97 & 12.90 \\
\hline \multicolumn{10}{|l|}{ Group C $^{d}$} \\
\hline GAH (16) & $23(22)$ & $6.40 \pm 4.56$ & $5.35 \pm 3.04$ & 5.47 & 4.88 & 0.56 & 2.30 & 23.94 & 16.33 \\
\hline GCA (31) & $43(41)$ & $10.08 \pm 9.77$ & $11.15 \pm 13.15$ & 7.36 & 7.07 & 1.02 & 1.60 & 45.76 & 58.70 \\
\hline GFA (16) & $22(23)$ & $7.21 \pm 3.59$ & $6.80 \pm 5.04$ & 6.66 & 5.30 & 3.06 & 2.02 & 19.83 & 25.94 \\
\hline GHA (10) & $13(12)$ & $6.93 \pm 3.66$ & $6.42 \pm 3.67$ & 7.09 & 6.35 & 1.30 & 1.19 & 12.92 & 15.95 \\
\hline GJA(8) & $22(22)$ & $30.17 \pm 38.21$ & $36.18 \pm 40.57$ & 9.76 & 10.72 & 0.59 & 2.30 & 122.78 & 126.98 \\
\hline GMK (6) & $10(9)$ & $5.01 \pm 3.12$ & $4.81 \pm 2.85$ & 4.91 & 4.20 & 0.71 & 0.52 & 10.75 & 10.20 \\
\hline All samples & $260(256)$ & $16.88 \pm 33.67$ & $16.75 \pm 29.77$ & 6.80 & 6.28 & 0.54 & 0.52 & 255.97 & 158.33 \\
\hline
\end{tabular}

${ }^{a} \mathrm{I}(\mathrm{O})$ means indoor (outdoor).

${ }^{\mathrm{b}}$ samples were collected between 12 and 16 collection times from each individual location.

${ }^{\mathrm{c}}$ samples were collected between 6 and 9 collection times from each individual location.

${ }^{d}$ the number between brackets indicates the number of sampling locations within each Governorate. 
$\sim 310$ million imperial gallons per day (MIGD) $(\sim 1.41$ million cubic meter per day $\left(\mathrm{Mm}^{3} / \mathrm{d}\right)$ of distillate $(331.5$ MIGD of potable water). In order to inhibit marine fouling inside the distillers, the sea water supply at each plant (total $\sim 18.7 \mathrm{Mm}^{3} / \mathrm{d}$ for the five plants) is chlorinated $(\sim 6.0 \mathrm{mg} / \mathrm{L}$ total residual chlorine) and used for both cooling and feeding the MSF distillation units. The $\mathrm{pH}$ of the produced distillate is adjusted by carbonation to 8.3 , blended with $5-10 \%$ of brackish water, chlorinated to total residual chlorine of $\sim 1.2$ $\mathrm{mg} / \mathrm{L}$ and pumped to the storage reservoirs, and from which to the distribution system network, where the consumers possess further storage facilities. For domestic or public premises, these facilities are mainly roof tanks $\left(6-12 \mathrm{~m}^{3}\right)$ constructed from fiberglass or polyethylene, in addition to ground reservoirs $\left(20-100 \mathrm{~m}^{3}\right)$ for large buildings. The supply of drinking water to various locations in regular operational conditions of the five desalination plants was: Az-Zoor (mean capacity of 115.2 MIGD) plant supplies completely the DUH location. Together with Shuaiba plant (36 MIGD) Az-Zoor supplies all locations at the GAH and GMK with various capacity ratios. Doha West (110.4 MIGD) and Doha East (50.4 MIGD) supplies mainly the CSE and GJA locations, respectively. The Shuwaikh (19.5 MIGD) plant supplies mainly the CSW location, while all other individual locations are fed by all of the plants with varying ratios depending on temporal demand.

The results of this study indicate that the levels of HAA5 are between $85 \%$ and $99 \%$ with an average of $95 \%$ of the THAAs levels. Table 1 depicts the statistical summary of the HAA5 levels found in various samples of the three groups of locations. It shows that:

1. The HAA5 mean values of samples collected from all locations of Group A were higher than those of the other Groups B and C, with the exception of GJA (Group C). This is evident by comparing the values of the $\boldsymbol{I}$ and $\boldsymbol{O}$ samples for all groups. The highest values of the $\boldsymbol{I}$ and $\boldsymbol{O}$ samples of Group A were higher than those of the highest values of other groups by $400 \%$ and $240 \%$, respectively. In addition, the lowest $I$ and $\boldsymbol{O}$ values of Group A were greater than the highest values of both Groups B and C by $66.5 \%$ and $59.6 \%$, respectively.

2. Among Group A locations, the highest HAA5 mean values for $\boldsymbol{I}$ and $\boldsymbol{O}$ samples were found in CSW $(50.22 \mu \mathrm{g} / \mathrm{L})$ and $\operatorname{CSE}(37.95 \mu \mathrm{g} / \mathrm{L})$, respectively, while the lowest values $16.78 \mu \mathrm{g} / \mathrm{L}$ and $17.80 \mu \mathrm{g} / \mathrm{L}$ were found in DUH.

3. The HAA5 mean value of $\boldsymbol{I}$ samples in CSW (Group A) showed a $62.7 \%$ increase over the $\boldsymbol{O}$ samples, while the means of the $\boldsymbol{O}$ samples in JOY (Group A) and GJA (Group C) were found higher than those of the $I$ samples by $16.8 \%$ and $19.9 \%$, respectively. All other locations of various groups showed slight differences in the $\boldsymbol{I}$ and $\boldsymbol{O}$ values.

4. The ranges of the HAA5 mean values for the $\boldsymbol{I}$ and $\boldsymbol{O}$ samples in Group B were $2.24-9.16 \mu \mathrm{g} / \mathrm{L}$ and 3.13 $10.05 \mu \mathrm{g} / \mathrm{L}$, respectively. These ranges were less than those for other groups $(16.78-50.22 \mu \mathrm{g} / \mathrm{L}$ and 17.80 $37.95 \mu \mathrm{g} / \mathrm{L}$ for Group A; $5.01-30.17 \mu \mathrm{g} / \mathrm{L}$ and 4.81 -
$36.18 \mu \mathrm{g} / \mathrm{L}$ for Group $\mathrm{C}$ in $\boldsymbol{I}$ and $\boldsymbol{O}$ samples, respectively).

5. The HAA5 mean values of the 22 samples of $\boldsymbol{I}(30.17$ $\mu \mathrm{g} / \mathrm{L})$ and $\boldsymbol{O}(36.18 \mu \mathrm{g} / \mathrm{L})$ collected from eight different locations in GJA (Group C) were higher compared to those found in the other five governorates (where the highest $\boldsymbol{I}$ and $\boldsymbol{O}$ values were $10.08 \mu \mathrm{g} / \mathrm{L}$ and $11.15 \mu \mathrm{g} / \mathrm{L}$, respectively) and were comparable to those of Group A locations.

Fig. (2a-c) illustrates the variation of HAA5 concentrations of $\boldsymbol{I}$ and $\boldsymbol{O}$ samples with the date of collection for CSW (Group A), CSO (Group B), and various eight locations in GJA (Group C), respectively. It is evident from Fig. (2a) that samples collected during the end of June and months of July, August, and December 2004 showed increased HAA5 levels, most of which exceeded the MCL set by the US-EPA $(60 \mu \mathrm{g} / \mathrm{L})$. The highest recorded HAA5 value $(255.97 \mu \mathrm{g} / \mathrm{L})$ was $427 \%$ that of the MCL. In January 2005 , the HAA5 values were much lower for the $\boldsymbol{I}$ and $\boldsymbol{O}$ samples $(22.27$ and $21.30 \mu \mathrm{g} / \mathrm{L})$ compared to that of the preceding month, December 2004 (71.96 and $67.07 \mu \mathrm{g} / \mathrm{L}$ ). Samples collected during the remaining months for the period from December 2003 to May 2005 showed much lower levels of HAA5 (highest $7.93 \mu \mathrm{g} / \mathrm{L}$ for $\boldsymbol{I}$ sample in June 13,2004) compared to either that of the MCL value or that of previously mentioned months. In addition, the HAA5 levels of $\boldsymbol{I}$ samples were increased relative to those of the $\boldsymbol{O}$ samples by $85.7 \%, 69.0 \%, 185 \%$, and $7 \%$ in June, July, August, and December 2004, respectively.

Fig. (2b), which represents one of Group B locations, shows that the HAA5 levels were far below the MCL for all samples collected. No samples were collected during the months of June, July, August, and December 2004 as they were for Group A locations. The highest HAA5 values were $13.97 \mu \mathrm{g} / \mathrm{L}$ for $\boldsymbol{I}$ at the FAR location and $15.10 \mu \mathrm{g} / \mathrm{L}$ for $\boldsymbol{O}$ at the CSO location (Table 1).

Fig. (2c), which represents the governorate GJA (Group C), shows that HAA5 levels of all samples collected from the five different locations on June 21, 2004 were high $(90.68$ to $126.64 \mu \mathrm{g} / \mathrm{L})$ as those of Group A and exceeded the MCL value. Also those of December 16, 2004 were fairly high (highest $46.46 \mu \mathrm{g} / \mathrm{L}$ ) compared to the values of other months (highest $11.09 \mu \mathrm{g} / \mathrm{L}$ ). These findings illustrate the higher HAA5 mean value in GJA compared to other governorates of Group C (Table 1), from which no samples were collected in June 2004. The figure shows that there is a great difference in HAA5 levels between the $\boldsymbol{I}$ and $\boldsymbol{O}$ samples in the samples collected from JWA in June $21(6.28$ $\mu \mathrm{g} / \mathrm{L}$ and $131.23 \mu \mathrm{g} / \mathrm{L})$ and December 16, $2004(16.10 \mu \mathrm{g} / \mathrm{L}$ and $57.42 \mu \mathrm{g} / \mathrm{L})$. The HAA5 levels of $I$ samples were decreased to $5 \%$ and $28 \%$ of the levels of the corresponding $\boldsymbol{O}$ samples at these sampling dates. This large decrease was due to the use of a commercial charcoal filter connected to the inside faucet (indoor). This technique is efficient in decreasing HAA5 levels, especially where they are higher than the MCL.

The previously presented data of various sampling groups (A, B, and C) indicate that the levels of HAA5 were found very high in most of all samples collected from 

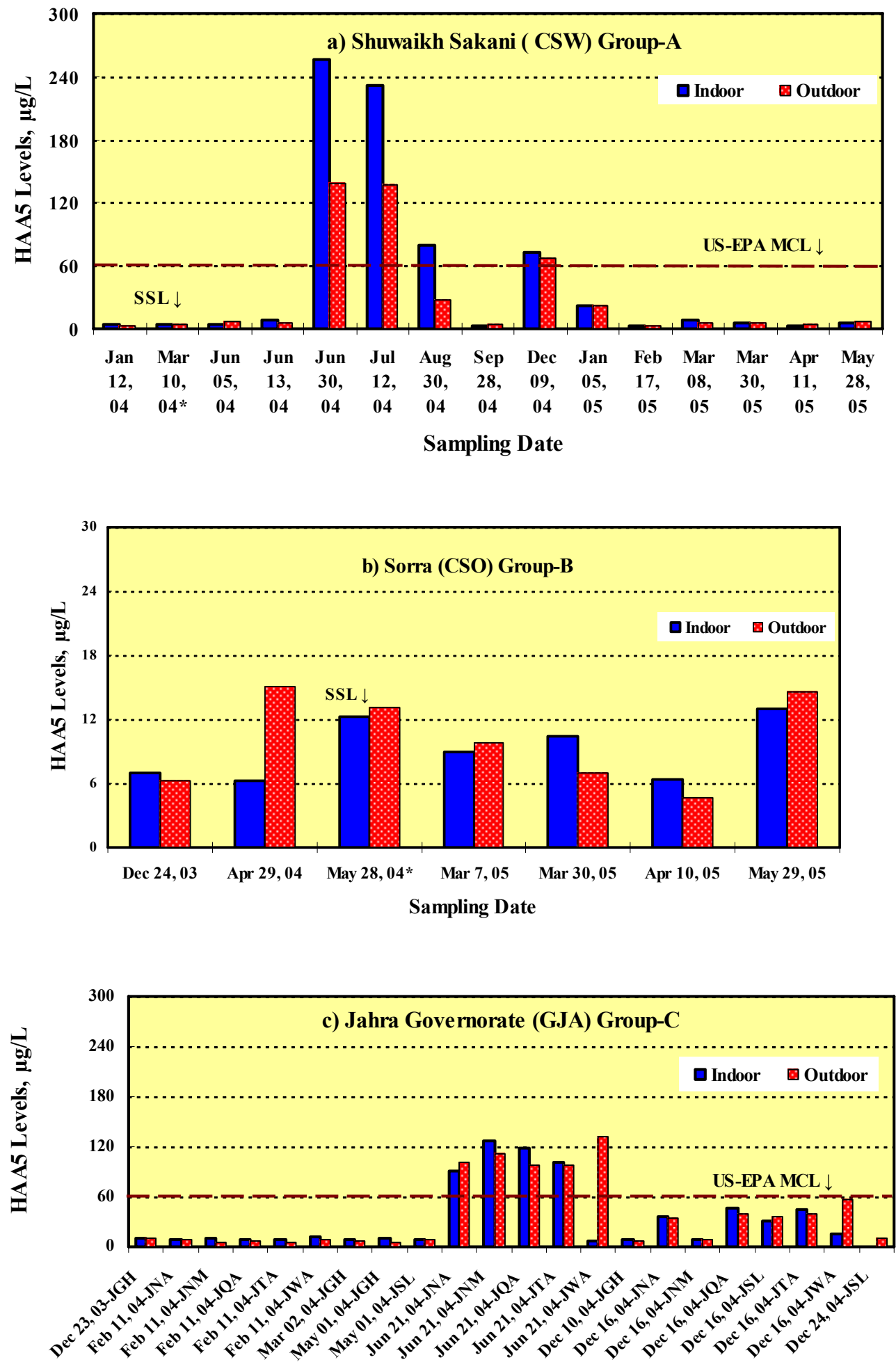

Sampling Date and Locations

Fig. (2). Variation of HAA5 levels in the $\boldsymbol{I}$ and $\boldsymbol{O}$ samples with sampling dates for three of selected locations. 
various locations at the end of June and the months of July, August, and December 2004 compared to those collected in other months. In order to obtain more information about these findings, a comparison of these levels between Group A locations (CSE, CSW, DUH, FRI, HSL, and JOY) is shown in Fig. (3). This figure illustrates and confirms that the levels were very low in the samples collected from all locations before the end of June 2004 (as seen also in Fig. 2a), and there were significant variations in the levels between various locations. In more details, Fig. (4) shows the variation of HAA5 mean values of all sampling locations in Groups A, B, and C during the months from December 2003 to May 2005. This figure illustrates that these levels were slightly changed from December 2003 until May 2004 and started to increase in June, and then reaching a maximum in July. They started to decrease in August to reach a minimum in September with no significant change to November. They increased again to reach a second maximum in December 2004, then started to decrease in January, and then reached a minimum from February to May 2005. This figure also illustrates that there is a slight difference between the values of the $\boldsymbol{I}$ and $\boldsymbol{O}$ samples, which is clearly evident in the July 2004 samples.

HAA5 levels of most samples collected from the secondary sampling locations (Fig. 1) mostly showed slight or no difference with those of the samples collected from primary locations (at approximate dates) from the same neighborhood (e.g., SSL in Figs. 2a, b). This indicates that the levels of HAA5 are mostly dependent on the date of collection and not on the sampling location (within the same neighborhood).

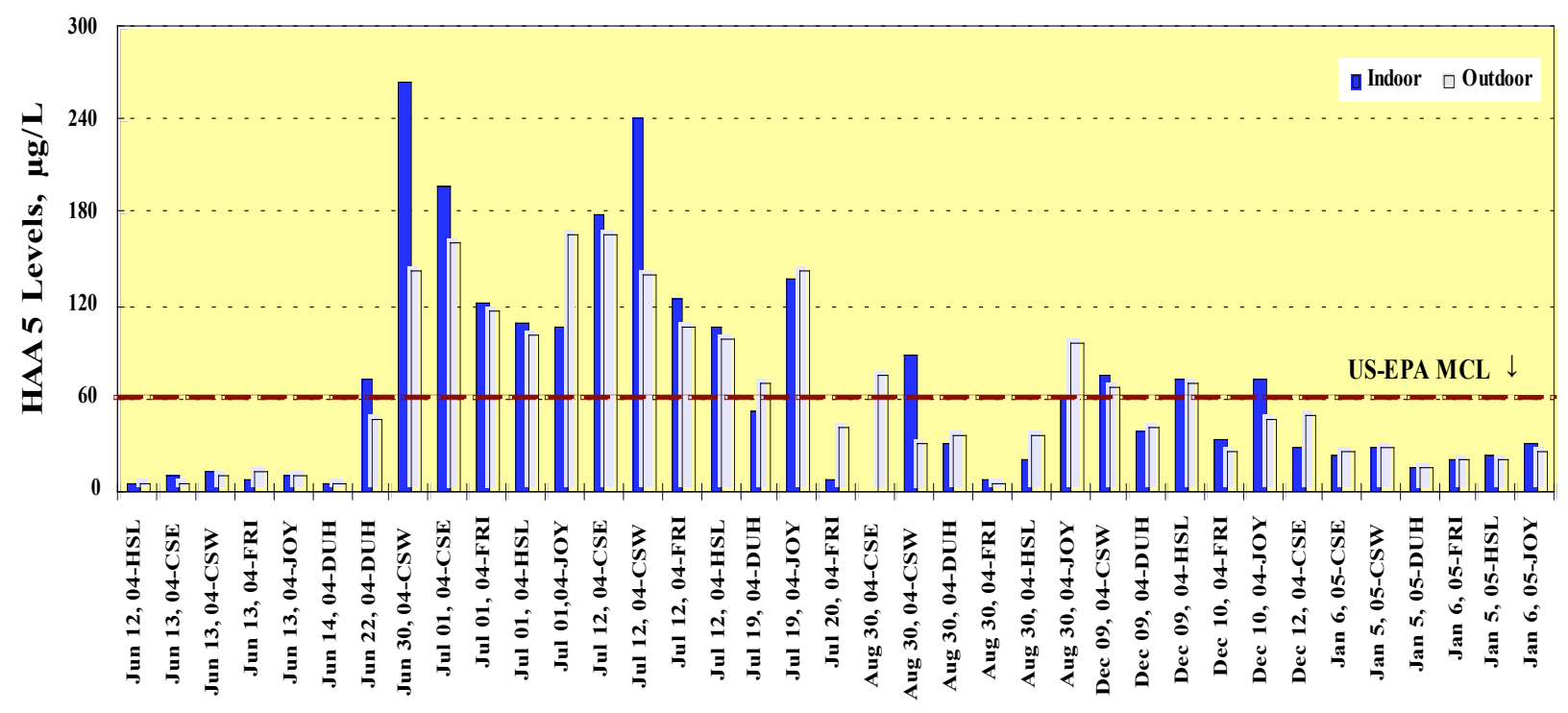

\section{Sampling Date and Locations}

Fig. (3). Variation of the high HAA5 levels in the $\boldsymbol{I}$ and $\boldsymbol{O}$ samples with sampling date for various Group A locations.

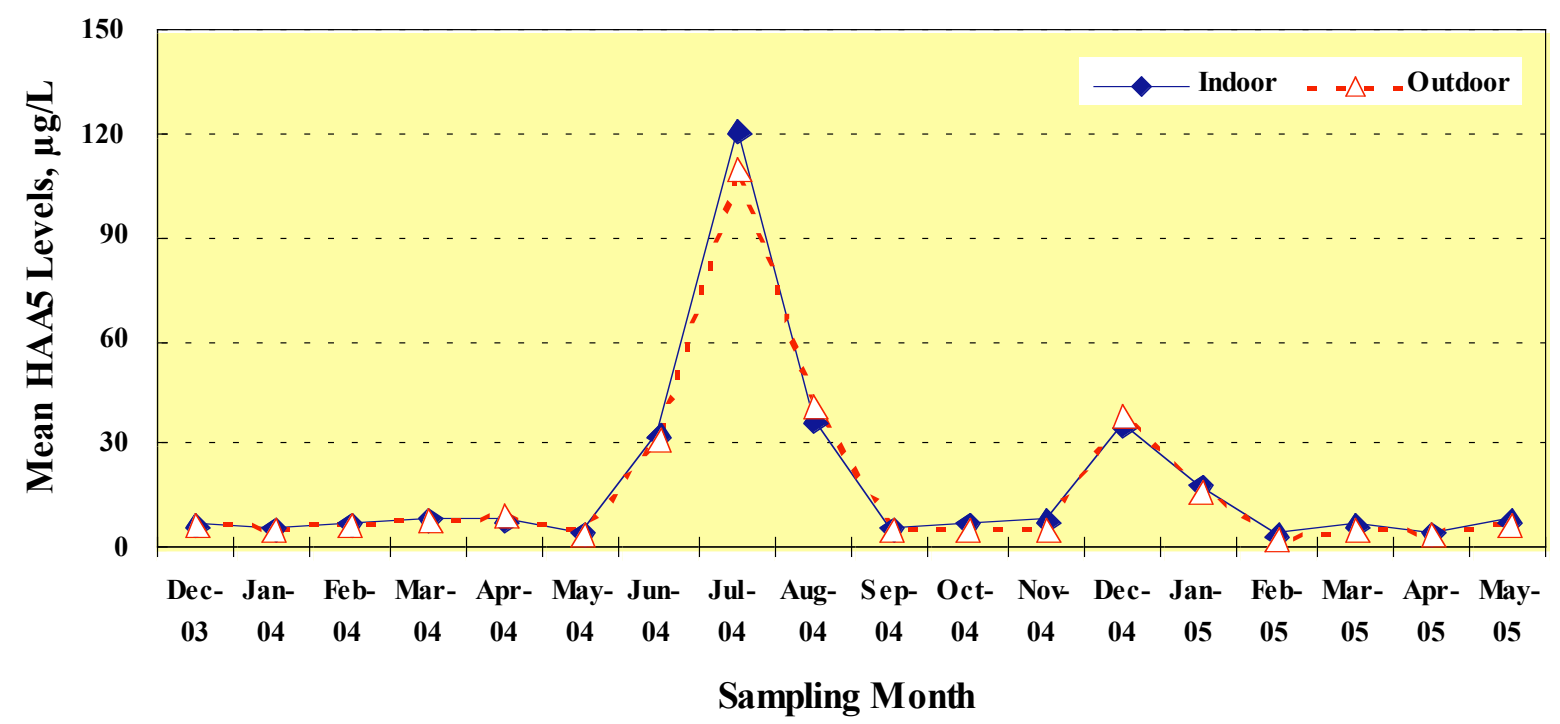

Fig. (4). Variation of the mean HAA5 levels between sampling locations in all Groups (A, B, and $\mathbf{C}$ ), the $\boldsymbol{I}$ and $\boldsymbol{O}$ samples, and sampling months. 
Table 2. Measured Water Quality Parameters

\begin{tabular}{|c|c|c|c|c|c|c|}
\hline \multirow{2}{*}{ Parameter } & \multicolumn{3}{|c|}{ Indoor } & \multicolumn{3}{|c|}{ Outdoor } \\
\hline & Min & Max & Mean \pm S. D. & Min & Max & Mean \pm S. D. \\
\hline $\mathrm{T}^{\circ} \mathrm{C}$ & 14.5 & 41.9 & $29.4 \pm 6.6$ & 15.4 & 43.8 & $32.4 \pm 5.3$ \\
\hline $\mathrm{pH}$ & 6.6 & 8.0 & $7.6 \pm 0.1$ & 7.0 & 8.1 & $7.6 \pm 0.1$ \\
\hline Cond, $\mu S$ & 55.8 & 876 & $542.2 \pm 116.9$ & 260.5 & 988.2 & $546.0 \pm 117.3$ \\
\hline $\operatorname{TDS}(m g / L)$ & 181.5 & 610.4 & $392.2 \pm 82.9$ & 181.6 & 571.5 & $392.6 \pm 84.7$ \\
\hline Res, $\mathrm{Cl}, m g / L$ & 0.00 & 0.97 & $0.32 \pm 0.17$ & 0.01 & 1.12 & $0.46 \pm 0.21$ \\
\hline $\mathrm{Br}^{-}(m g / L)$ & 0.10 & 4.75 & $0.54 \pm 0.80$ & 0.10 & 4.76 & $0.60 \pm 0.97$ \\
\hline
\end{tabular}

Table 2 shows that there were significant variations in the measured temperatures in both indoor $\left(14.5-41.9^{\circ} \mathrm{C}\right)$ and outdoor $\left(15.4-43.8^{\circ} \mathrm{C}\right)$ samples. The mean values of $\mathrm{pH}$ show no difference between the indoor and outdoor samples. As expected, the measured values of residual chlorine were found higher for the $\boldsymbol{O}$ samples compared to those of the $\boldsymbol{I}$ samples. The bromide ion was detected in $11.7 \%$ of the samples analyzed and the highest value of $4.76 \mathrm{mg} / \mathrm{L}$ is found. Also, the mean value of the $\boldsymbol{O}$ samples was higher than those of the $I$ samples.

Analysis of the data showed that HAA5 levels exceeded the MCL $(60 \mu \mathrm{g} / \mathrm{L})$ in $8 \%$ of the total samples analyzed $(516$ samples). The percent increase of HAA5 levels was found between $6 \%$ and $327 \%$ of the MCL value, with an average of $106 \%$. The significant variations existing in these levels between the sampling dates, various locations, and the $\boldsymbol{I}$ and $\boldsymbol{O}$ points for the same location can be explained by several factors. For chlorinated drinking water, these include source water, chlorine dosage, residual chlorine in the distribution system and its contact time, temperature, $\mathrm{pH}$, and precursor concentrations [18-20]. It may vary from one location to another and from one date to another, as well as from one desalination plant to another [26]. Fig. (5) shows the relationship between the levels of HAA5 with residual chlorine levels and sampling temperatures. Strong correlations between residual chlorine and HAA5 were found in this study, as previously reported for the THMs studied in the same water samples [23]. The s higher recorded HAA5 levels in the $\boldsymbol{I}$ samples collected on the sampling dates of 30 June, 12 July and 30 August 2004 relative to the $\boldsymbol{O}$ samples at the CSW location (Fig. 2a) can be explained by the very low percentages $(13.3 \%, 0.0 \%$ and $21.7 \%)$ and very high percentages $(86.8 \%, 80.2 \%$ and $86.8 \%$ ) of residual chlorine levels in $\boldsymbol{I}$ (Fig. 5a) and $\boldsymbol{O}$ (Fig. 5b) samples, respectively. It is evident that the variable high and low recorded values of HAA5 in the $\boldsymbol{I}$ and $\boldsymbol{O}$ samples from all locations may be correlated with residual chlorine levels as was found in the CSW location (Fig. 5). In addition, sampling temperature appears to have a significant effect on HAA5 levels as evident in Figs. (2a, c, 5). On the other hand, $\mathrm{pH}$ has no effect, as there was no change in its value during the study period (7.12 - 7.69). As we previously mentioned, water comes to the indoor tap from the rooftop storage tank that is fed from an underground reservoir. This means that the outdoor water, which comes directly from the storage facilities of the distribution system, stays in the reservoir and rooftop tank (under direct exposure to sunlight and outdoor temperature) for variable periods of time depending on the water flow inside the building. This situation greatly affects the residence time of chlorine and consequently its concentration, which plays an important role in the formation of HAAs, including HAA5 components detected in the indoor samples.

It can be concluded from the previous discussion that the water supply from the Az-Zoor plant (servicing DUH, GAH, and GMK) contains the lowest HAA5 levels, while that of Doha East (servicing GJA and JOY), Doha West (servicing CSE) and Shuwaikh (servicing CSW) contain the highest levels. In addition to the previously discussed factors, this may be because Doha and Shuwaikh plants are on the shore of Kuwait Bay (Fig. 1); the main commercial marine port of Kuwait is less than one $\mathrm{km}$ northwest of the Shuwaikh plant. The intake water of these desalinated plants are in or very close to Kuwait Bay, which is subject to elevated pollution by organic compounds resulting from heavy ship traffic. This elevates the levels of precursors. On the other hand, the Az-Zoor plant is on the far south of the Kuwait shore. Its intake water is much less polluted with organics and therefore has a lower level of precursors. The intake water of the Shuaiba plant may be nearly the same as Az-Zoor, but we cannot evaluate its product because it services all locations.

Table 3 depicts the summary statistics of the five HAA5 components. The percent detection frequencies were in the order MBAA $>$ DBAA $>$ DCAA $>$ TCAA $>$ MCAA. As listed in Table 4 and shown in Fig. (6), the percent dominance frequencies for HAA5 components were found in the order TCAA $(43 \%)>$ MCAA $(23 \%)>$ MBAA $(22 \%)>$ DBAA $(9 \%)>$ DCAA $(4 \%)$. In addition, the percent dominance of the nine HAA components were TCAA $(34 \%)$ $>\operatorname{MCAA}(18 \%)>\operatorname{MBAA}(17 \%)>\mathrm{CDBAA}(9 \%)>\mathrm{DBAA}$ $(7 \%)>\operatorname{BDCAA}(6 \%)>\operatorname{TBAA}(4 \%)>\operatorname{DCAA}(3 \%)>$ BCAA (2\%). These findings are different from those previously reported by studies on the desalinated water produced in SA [21] and UAE [22]. The inside and downstream samples of the desalination plant in UAE [22] showed nominal levels of HAA5 components, except for the DBAA component that was found in the range of $0.52-13.4$ $\mu \mathrm{g} / \mathrm{L}$. In contrast, DBAA exhibited the second lowest level in this study. Also, analysis of the product water from the Al-Jubail desalination plant, SA, revealed that the estimated mean values of TCAA, DCAA, and BCAA were $0.80,0.60$, and $0.16 \mu \mathrm{g} / \mathrm{L}$, respectively [21]. Other HAA5 components were not detected in any of their samples. Furthermore, other 


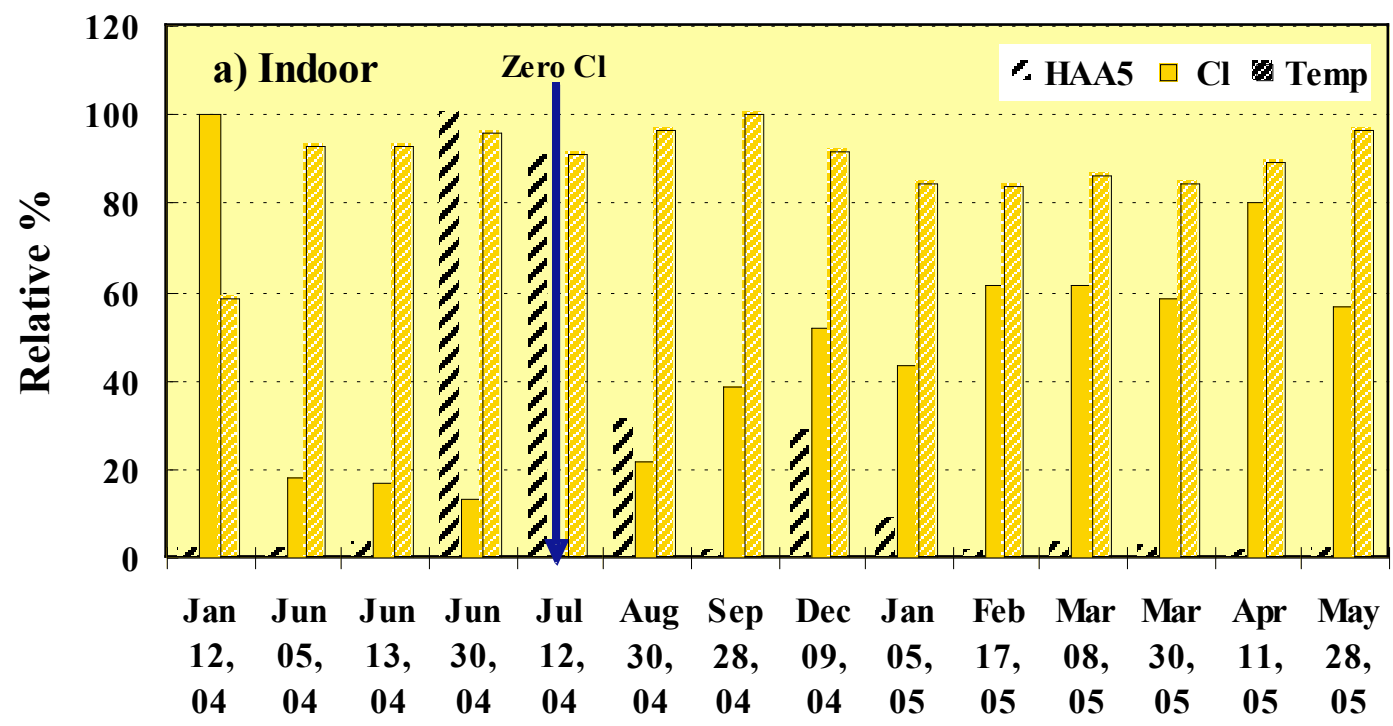

\section{Sampling date}

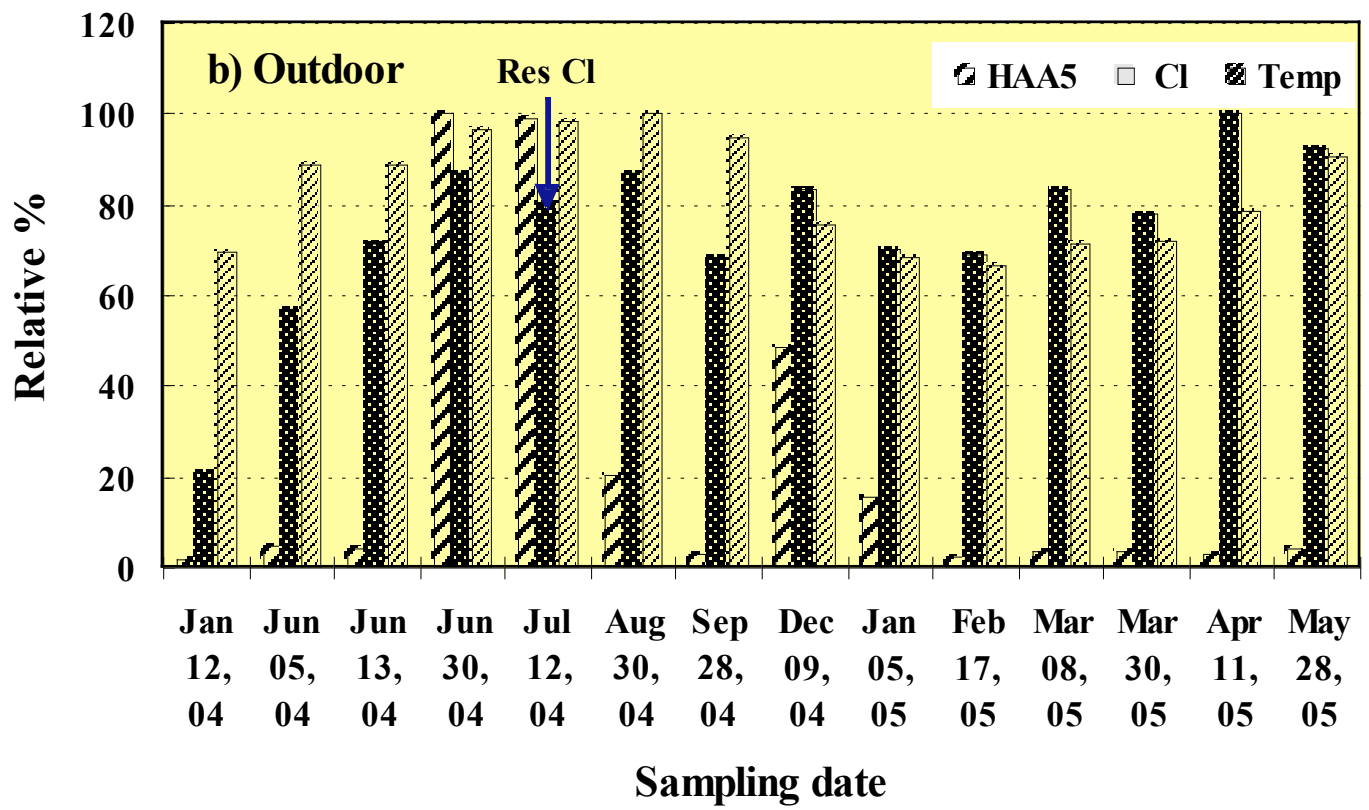

Fig. (5). Relative measurement of HAA5, residual chlorine and temperature for the $\boldsymbol{I}$ and $\boldsymbol{O}$ samples of CSW from Group A sampling locations (the highest values of each are represented as 100\%).

studies of drinking water obtained from surface water sources reported that the highest levels among HAA components were of TCAA and DCAA [27-29], and the brominated ones were the lowest. In this study, the higher levels and detection frequency of MBAA relative to those found in all previous studies [21, 22, 27-29] may be attributed to the prevalence of bromide in the source seawater. Brominated acetic acids are formed during the disinfection of water that contains bromide ions and organic matter [30, 31]. Bromide ions occur naturally in surface water, seawater, and groundwater and exhibit seasonal fluctuations in levels. Bromide ion levels can increase due to saltwater intrusion resulting from drought conditions or due to pollution [32]. Brominated acetates are generally present in drinking water distribution systems at mean concentrations below $5 \mathrm{mg} / \mathrm{L}$ [33]. In a survey of 20 drinking water samples prepared from different sources in the Netherlands, HAAs were found in all samples prepared from surface water, whereas they could not be detected in samples prepared from groundwater [34]. It was reported that brominated acetic acids account for $65 \%$ of the THAAs concentration. On the other hand, TCAA, DCAA and MCAA were the most commonly encountered HAAs in the drinking water in Athens, Greece [35], and MCAA was the most abundant compound. Malliarou et al. [29] assessed the levels of HAAs and their relationship to THMs, temperature, $\mathrm{pH}$, and free and total chlorine. They found that the means of HAA levels ranged from 35-95 $\mu \mathrm{g} / \mathrm{L}$ with a maximum concentration of $244 \mu \mathrm{g} / \mathrm{L}$, and the ratio of TTHM and THAA levels was significantly correlated with temperature, $\mathrm{pH}$, and free and total chlorine. The DCAA levels were fairly high (above $100 \mu \mathrm{g} / \mathrm{L}$ ), while TCAA levels were lower. 
Table 3. Statistical Summary of HAA5 Components

\begin{tabular}{|c|c|c|c|c|c|c|c|c|c|c|}
\hline \multirow{3}{*}{ Parameters } & \multicolumn{10}{|c|}{ Concentration of HAA5 Components, $\mu \mathrm{g} / \mathrm{L}$} \\
\hline & \multicolumn{2}{|c|}{ MCAA } & \multicolumn{2}{|c|}{ MBAA } & \multicolumn{2}{|c|}{ DCAA } & \multicolumn{2}{|c|}{ TCAA } & \multicolumn{2}{|c|}{ DBAA } \\
\hline & $I$ & $\boldsymbol{O}$ & $I$ & $\boldsymbol{O}$ & $I$ & $\boldsymbol{O}$ & $I$ & $\boldsymbol{O}$ & $I$ & $\boldsymbol{O}$ \\
\hline Mean & 7.32 & 8.19 & 7.26 & 7.44 & 1.39 & 1.22 & 14.56 & 14.30 & 3.16 & 2.59 \\
\hline STD Dev & 13.92 & 14.75 & 15.67 & 14.78 & 1.44 & 0.90 & 25.68 & 22.62 & 1.97 & 1.70 \\
\hline Median & 1.44 & 1.49 & 1.48 & 1.24 & 0.88 & 0.78 & 5.40 & 5.35 & 2.88 & 5.91 \\
\hline Minimum & 0.41 & 0.50 & 0.50 & 0.50 & 0.50 & 0.50 & 0.50 & 0.50 & 0.16 & 0.50 \\
\hline Maximum & 67.98 & 63.98 & 104.80 & 66.62 & 10.65 & 6.95 & 128.77 & 101.33 & 9.06 & 8.69 \\
\hline Count & 106 & 100 & 153 & 160 & 126 & 131 & 126 & 119 & 149 & 155 \\
\hline$\%$ Detection Frequency & 40.93 & 38.76 & 59.07 & 62.02 & 48.65 & 50.78 & 48.65 & 46.12 & 57.53 & 60.08 \\
\hline$\%$ dominance* & \multicolumn{2}{|c|}{23} & \multicolumn{2}{|c|}{22} & \multicolumn{2}{|c|}{4} & \multicolumn{2}{|c|}{43} & \multicolumn{2}{|c|}{9} \\
\hline
\end{tabular}

* The $\%$ dominance $=($ mean value of the HAA5 component $/$ the total means of the five HAA5 components $) \times 100$.

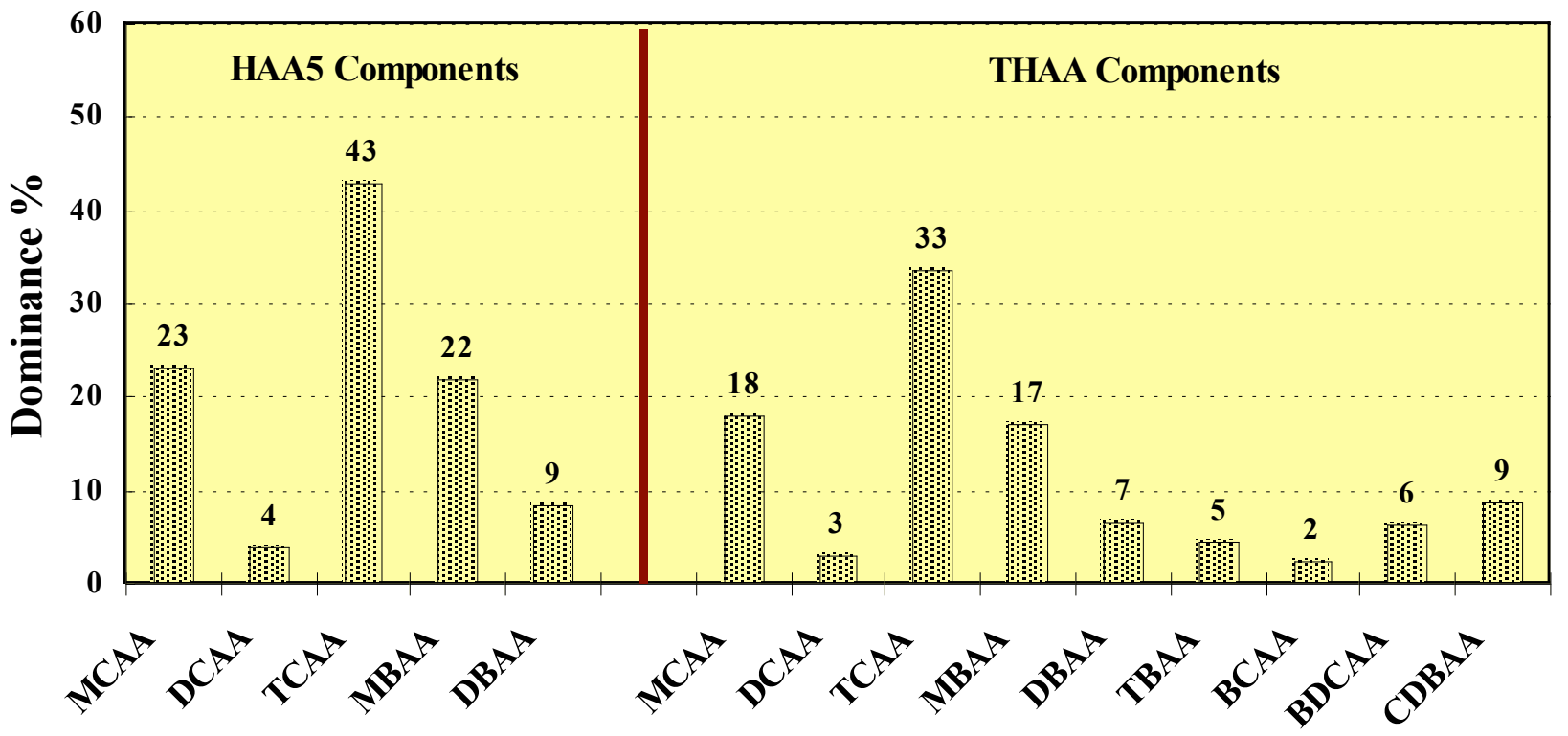

THAA and HAA5 species

Fig. (6). Variation of the dominance percent for various components of HAA5 and HAAs.

In the Arabian Gulf region in general and Kuwait in particular, climatic changes during the year are specific and considerably different from those in other geographic regions. The usual four seasons are not present; instead, winter and summer conditions are the most prevailing. Winters are short (December to March) and fairly cold (-2$28^{\circ} \mathrm{C}$ ), whereas summers are relatively long (April to November) but generally hot $\left(24-55^{\circ} \mathrm{C}\right)$. Consequently, differences in water temperature between those periods can be greater than $25^{\circ} \mathrm{C}$. This factor may contribute to significant changes in water quality, and depending on operational adjustments during the desalination and treatment processes (including the chlorination step), may also contribute to seasonal changes in HAA5 levels over the course of the year. Indeed, seasonal variations were found in this study. Fig. (7) shows the seasonal variations of HAA5 mean values in various individual locations of Group A and the GJA governorate of Group C. In agreement with previous studies [7, 9, 27, 28, 35], there were higher variations of HAA5 mean values in the summer compared to that in the winter as shown in Fig. (7a). These variations differ with various sampling locations. As seen in Fig. (7b), the highest percent increase, $700 \%$ and $620 \%$, in the $\boldsymbol{I}$ and $\boldsymbol{O}$ samples, respectively, were found at the FRI location. On the other hand, the lowest increase $30 \%$ was found in the $\boldsymbol{I}$ samples with no change in that of the $\boldsymbol{O}$ samples at the DUH location. The percent increase in the $I$ samples at the CSW location was more than $100 \%$ greater than those of the $\boldsymbol{O}$ samples, while there were only slight or no differences encountered at the other locations. 

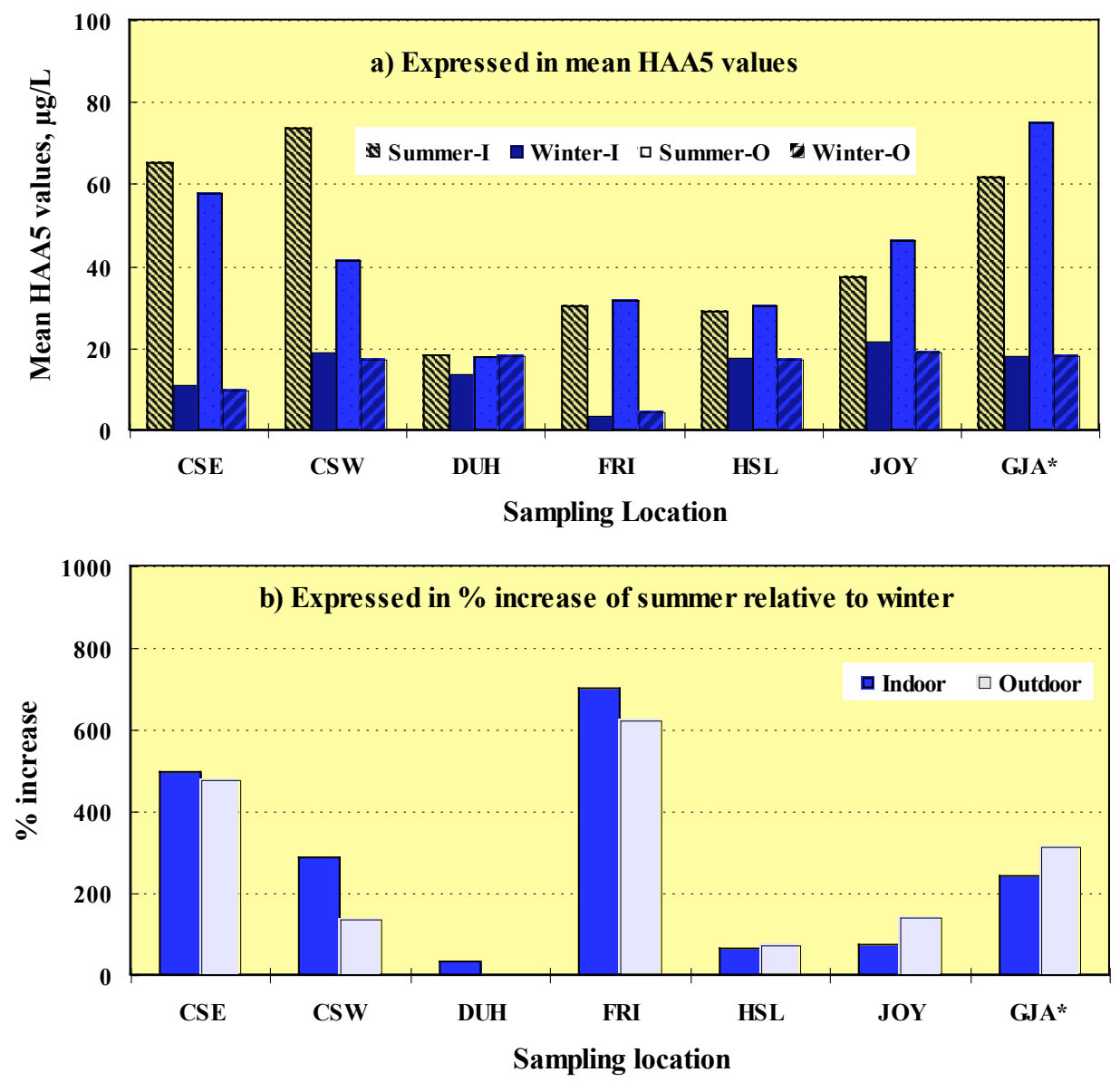

Fig. (7). Seasonal variation of HAA5 in various Group A locations and GJA governorate of Group-C. Winter: December - March; summer: April-November. * Mean values of 22 collections from 8 locations.

The findings of this study may be better explained in view of more data on the water quality parameters, residual chlorine, bromide, HAAs levels in the intake water, as well as desalinated water through various operational stages including the final stage of blending and chlorination. However, the authors were not able to obtain permission from the Kuwaiti MEW authorities for performing these studies in the desalination and water treatment facilities.

Dalapon, a halogenated organic acid (2, 2-dichloroproprionic acid), was detected along with other components of HAAs. Dalapon is a herbicide used to control grasses in a wide variety of crops. It was not initially considered in the study objectives, but after its detection in some water samples (according to US-EPA method 552.2, which includes HAAs and dalapon), it was included in the analysis. In a literature survey on the existence of HAAs in drinking water, no reports mentioned the detection of dalapon. To our knowledge, this is the first study that has documented the existence of dalapon in drinking water. Dalapon was found in $9 \%$ of the water samples analyzed for HAAs (516 samples) with levels much lower than the MCL value set by US-EPA $(200 \mu \mathrm{g} / \mathrm{L})$. Table 4 illustrates the detected levels of dalapon at various locations. The highest level detected was $13.41 \mu \mathrm{g} / \mathrm{L}$, and the mean values for the $\boldsymbol{I}$ and $\boldsymbol{O}$ samples were $4.69 \pm 3.11$ and $5.28 \pm 4.36 \mu \mathrm{g} / \mathrm{L}$, respectively. The highest levels detected were found in samples collected during January 2005. It is generally known that the movement of seawater in the Arabian Gulf comes from the Ocean in the northeast direction (along the western shores of Iran and south of Iraq) and reverts to the southeast direction along the eastern shores of Kuwait. Therefore, we presume that dalapon was primarily from Gulf seawater (source of desalinated water), which is polluted by runoff from its agricultural use in the neighbouring Gulf countries Iran and Iraq.

\section{Bottled Water}

Our previous study of organic contaminants in drinking water in Kuwait reported the detection of THMs in $65 \%$ of bottled water samples with maximum THMs concentration of $37.55 \mu \mathrm{g} / \mathrm{L}$ and mean value of $11.6 \pm 12.18 \mu \mathrm{g} / \mathrm{L}$ [36] brought to our attention the possibility that HAAs may also be found in some bottled water brands, particularly those prepared from treated tap water. Therefore, 51 brands of bottled water imported from Gulf, Arab and European countries, in addition to three local brands, were analyzed for HAAs and dalapon. HAAs were detected in 31 brands from SA (13), UAE (7), Kuwait (3), four European countries (5) and two Arab countries (3). The lowest and highest THAA levels were 0.73 and $10.01 \mu \mathrm{g} / \mathrm{L}$, respectively. The mean value $4.86 \pm 2.49 \mu \mathrm{g} / \mathrm{L}$ was found. The highest value was much lower than the MCL set by the US-EPA. The haloacetic acids DBAA, BCAA and CDBAA were not detected, and MCAA was the most predominant among the 
Table 4. Levels of Detected Dalapon in Household Drinking Water

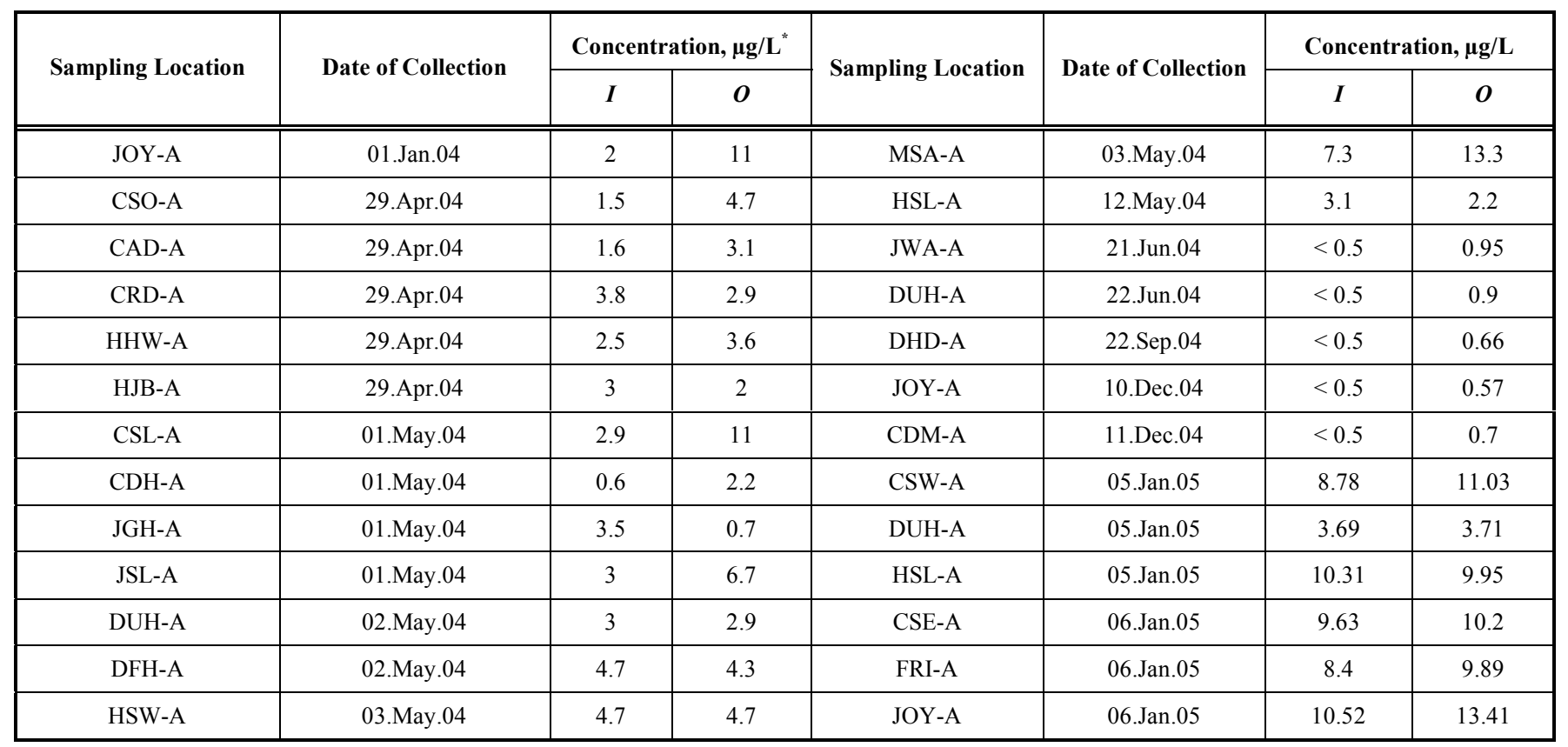

other ones found. The detection of HAAs was generally consistent with the presence of THMs found in the previous study [36].

\section{CONCLUSIONS}

HAAs were analyzed in 516 water samples collected from private residences (houses and apartments) and government buildings at 99 locations in 69 neighborhoods of the six governorates of the State of Kuwait from December 2003 to May 2005. The analysis involved two points at each sampling location (indoor and outdoor), leading to the following conclusions:

1. HAAs were detected in all water samples studied. The levels of HAA5 were between $85 \%$ and $99 \%$ of THAA levels, with an average of $95 \%$.

2. HAA5 levels exceeded the MCL $(60 \mu \mathrm{g} / \mathrm{L})$ in $8 \%$ of the total analyzed samples. The percent increase of HAA5 levels was between $6 \%$ and $327 \%$ of the MCL value, with an average of $106 \%$.

3. HAA5 levels of the indoor samples were generally higher than outdoor samples.

4. An indoor charcoal filter showed significant efficiency in decreasing HAA5 levels.

5. The lowest HAA5 mean value was found at the DUH location serviced by the Az-Zoor plant, while the highest values were found at the CSE, CSW and JOY locations serviced by the Doha and Shuwaikh plants.

6. The percent dominance frequencies for HAA5 components were found in the order TCAA (43\%), MCAA (23\%), MBAA (22\%), DBAA (9\%), and DCAA (4\%).

7. Strong correlations between residual chlorine and HAA5 levels were observed.
8. HAA5 levels in indoor and outdoor samples were higher in the summer than in the winter.

9. Dalapon was detected at levels below the MCL value set by the US-EPA $(200 \mu \mathrm{g} / \mathrm{L})$ in $9 \%$ of analyzed samples

10. HAA5 was detected in 31 brands of bottled water at levels below the MCL value set by the US-EPA (60 $\mu \mathrm{g} / \mathrm{L})$.

11. A further study on the intake and desalinated waters (through various desalination, blending, and chlorination stages) with cooperation of the Kuwaiti MEW authorities is recommended.

\section{ACKNOWLEDGEMENTS}

The authors acknowledge and express their thanks and appreciation to the Kuwait Foundation for the Advancement of Sciences (KFAS) for financial support of this study (grant \# 2001-1505-03), and the Public Authority for Applied Education and Training (PAAET) for partial financial support and guidance. Special thanks are extended to the Organic Lab Staff, University of Iowa Hygienic Laboratory (UHL), Iowa City, Iowa, USA for their kind assistance, guidance, and technical support.

\section{REFERENCES}

[1] Richardson SD. Disinfection by-products and other emerging contaminants in drinking water. Trends Anal Chem 2003; 22: 66684.

[2] Ellis KV. Water disinfection: a review with some consideration of the requirements of the Third World. CRC Crit Rev Environ Control 1991; 20: 341-7.

[3] Morris RD, Audet AM, Arogelillo IF, Chalmers TC, Mosteller F. Chlorination, chlorination by-products and cancer: a meta-analysis. Am J Public Health 1992; 82: 955-63.

[4] Villanueva CM, Kogevinas M, Grimalt JO. Drinking water chlorination and adverse health effects: a review of epidemiological studies. Med Clin 2001; 117: 27-35.

[5] Richardson SD, Simmons JE, Rice G. Disinfection byproducts: the next generation. Environ Sci Technol 2002; 36: 198A-205A. 
[6] Deborde M, von Gunten U. Reactions of chlorine with inorganic and organic compounds during water treatment- Kinetics and mechanisms: a critical review. Water Res 2008; 42: 13-51.

[7] Arora H, LeChevallier MW, Dixon KL. DBP occurrence survey. J Am Water Works Assoc 1997; 89: 60-8.

[8] Steven AA, Symons JM. Alternative Disinfection Processes, Organic Carcinogenic Drinking Water. In: Ram NM, Calabrese E, Christman RF, Eds. New York: Wiley 1986; p. 183.

[9] Krasner SW, McGuire MJ, Jacaugelo JG. The occurrence of disinfection by-products in US drinking water. J Am Water Works Assoc 1989; 81: 41-53.

[10] Villanueva CM, Cantor KP, Cordier S, et al. Disinfection byproducts and bladder cancer. A pooled analysis. Epidemiology 2004; 15: 357-67.

[11] Toledano MB, Nieuwenhuijsen MJ, Bennet J, et al. Chlorination disinfection byproducts and adverse birth outcomes in Great Britain: birthweight and still birth. Environ Health Perspect 2005; 113: 225-32.

[12] Cool HJ, Van Kseiji CF, Hrubec F. In: Jolly RL, Condie LW, Johnson JD, et al., Eds. Water Chlorination: Chemistry Environmental Impact and Health Effects. USA: Lewis, Chelsea, MI 1985; Vol. 5: p. 227...

[13] Krishna G, Swarupa TS, Luc BJ, Prabha DS. Chlorination byproducts, their toxicodynamics and removal from drinking water. J Hazard Mater 2007; 140: 1-6.

[14] Cantor KP. Drinking water and cancer. Cancer Causes Control 1977; 8: 292-308.

[15] Nieuwenhuijsen MJ, Toledano MB, Eaton N, Fawell J, Elliott P. Chlorination disinfection byproducts in water and their association with adverse reproductive outcomes: a review. Occup Environ Med 2000; 57: 73-85.

[16] Graves CG, Matanuska GM, Tardiff RG. Weight of evidence for an association between adverse reproductive and developmental effects and exposure to disinfection by-products: a critical review. Regul Toxicol Pharmacol 2001; 34: 103-24.

[17] Bove F, Shim Y, Zeitz P. Drinking water contaminants and adverse pregnancy outcomes: a review. Environ Health Perspect 2002; 110 (Suppl 1): 61-74.

[18] Rodriguez MJ, Serodes J, Levallois P. Behaviour of trihalomethanes and haloacetic acids in a drinking water distribution system. Water Res 2004; 38: 4367-82.

[19] Rodriguez MJ, Serodes J, Roy D. Formation and fate of haloacetic acids (HAAs) within the water treatment plants. Water Res 2007; 41: 4222-32.

[20] Sadiq R, Rodriguez MJ. Disinfection byproducts (DBPs) in drinking water and predictive models for their occurrence: a review. Sci Total Environ 2004; 321: 21-46.

[21] Dalvi AGI, Al-Rasheed R, Javeed MA. Haloacetic acids (HAAs) formation in desalination processes from disinfectants. Desalination 2000; 129: 261-71.
[22] Elshorbagy W, Abdulkarim M. Chlorination byproducts in drinking water produced from desalination in United Arab Emirates. Environ Monit Assess 2006; 123: 313-31.

[23] Al-Mudhaf HF, Abu-Shady AI. Trihalomethane levels and their seasonal variation in drinking water produced from thermal desalination in Kuwait. Open Environ Sci 2008; 2: 88-100.

[24] US Environmental Protection Agency (US-EPA). Methods and guidance for analysis of water. Office of Water, Washington DC 20460. 1999; EPA 821-C-99-004.

[25] US Environmental Protection Agency (US-EPA). 2004 ed. of the Drinking Water Standards and Health Advisories. Office of Water Washington DC. Winter 2004; EPA 822-R-04-005.

[26] Ali MY, Riley JP. Distribution of halomethanes in potable waters of Kuwait. Water Res 1990; 24: 533-8.

[27] Singer PC, Obolensky A, Greiner A. DBPs in chlorinated North Carolina drinking water. J Am Water Works Assoc 1995; 87: 8392.

[28] Nissinen TK, Miettiene IT, Martikainen PJ, Vartiainen T. Disinfection by-products in Finnish drinking water. Chemosphere 2002; 48: 9-20.

[29] Malliarou E, Collins C, Graham N, Nieuwenhuijsen MJ. Haloacetic acids in drinking water in the United Kingdom. Water Res 2005; 39: 2722-30

[30] IPCS. Disinfectants and disinfectant by-products. Geneva, World Health Organization, International Programme on Chemical Safety, Environmental Health Criteria 216, 2000.

[31] World Health Organization (WHO) 2003. Brominated acetic acids in drinking-water. Geneva: World Health Organization. 2003; WHO/SDE/WSH/03.04/79.

[32] Jacangelo JG, Patania NL, Reagan KM, Aieta EM, Krasner SW, McGuire MJ. Ozonation: assessing its role in the formation and control of disinfection by-products. J Am Water Works Assoc 1989; 81: 74-84.

[33] US Environmental Protection Agency (US-EPA). Drinking water criteria document for brominated acetic acids. Washington, DC, US Environmental Protection Agency, Health and Ecological Criteria Division, Office of Science and Technology, Office of Water, 2003.

[34] Pourmoghaddas H, Stevens AA, Kinman RN, Dressman RC, Moore LA, Ireland JC. Effect of bromide ion on formation of HAAs during chlorination. J Am Water Works Assoc 1993; 85: 827.

[35] Golfinopoulos SK, Nikolaou AD. Survey of disinfection byproducts in drinking water in Athens, Greece. Desalination 2005; 176: 13-24.

[36] Al-Mudhaf HF, Alsharifi FA, Abu-Shady AI. Survey of organic contaminants in household and bottled drinking waters in Kuwait. Sci Total Environ 2009; 407: 1658-86. 